\title{
Lakes and rivers as microcosms, version 2.0
}

\author{
David G. JENKINS*
}

Department of Biology, University of Central Florida, 4000 Central Florida Blvd., Orlando, FL, USA 32816-2368

*Corresponding author: david.jenkins@ucf.edu

\section{ABSTRACT}

Limnology has been greatly influenced by The lake as a Microcosm (Forbes, 1887), which described a holistic focus on the internal machinations of singular, island-like aquatic ecosystems. I consider three persistent influences of The lake as a Microcosm: as an organizing paradigm for the teaching of limnology relative to its practice; the idea that inland waters are like islands, and the replicability of types of inland waters. Based on inspection of recent peer-reviewed literature and 32 limnology texts, we teach limnology according to Forbes but do not practice it in that holistic context. Instead, we practice limnology as aquatic ecology. Based on novel analyses of species-area relationships for 275 inland waters and 392 islands, inland waters are more like continental habitat patches than islands; the island metaphor is poetic but not accurate. Based on a quantitative review of beta diversity (40 data sets representing 10,576 inland waters and 26 data sets representing 1529 terrestrial sites), aquatic systems are no more replicable than are terrestrial systems; a typological approach to limnology is no more justified than it is in terrestrial systems.

I conclude that a former distinction between limnology and aquatic ecology no longer applies, and that we should define limnology as the ecology of inland waters. Also, we should not consider lakes and rivers as islands that represent other systems of the same type, but should consider them as open, interactive habitat patches that vary according to their geology and biogeography. I suggest modern limnology operates according to 3 paradigms, which combine to form 3 broad limnological disciplines and establish a basis for a plural, interactive view of lakes and rivers as microcosms. This model of modern limnology may help better connect it to ecology and biogeography and help limnology be even more relevant to science and society

Key words: limnology, aquatic ecology, biogeography, paradigms, species-area relationships, beta diversity.

Received: May 2013. Accepted: August 2013.

\section{INTRODUCTION}

"One finds in a single body of water a far more complete and independent equilibrium of organic life and activity than on any equal body of land. It is an islet of older, lower life in the midst of the higher more recent life of the surrounding region. It forms a little world within itself, - a microcosm within which all the elemental forces are at work and the play of life goes on in full, but on so small a scale as to bring it easily within the mental grasp."

$$
\text { S.A. Forbes (1887) }
$$

\section{A singular view}

Few papers published in similarly remote outlets will have the long-term impact of Forbes' The lake as a Microcosm, first published in 1887 in the Bulletin of the Scientific Association (Peoria, IL, USA). It is well known because it has been reprinted in multiple formats, including as the first paper in the popular Foundations of Ecology (Real and Brown, 1991). It has been especially relevant in limnology but it also represents an early view of key and persistent concepts in ecology, including population, community, and ecosystem ecology.

Three important, interacting themes for limnology emerge from The lake as a Microcosm and are the subject of this paper: i) The ecosystem concept is an organizing framework for limnology. Forbes' early description of a lake as a microcosm (note the singular of each) is important because it was the antecedent of the ecosystem concept's integrated view of interactive biota in a physicochemical context (McIntosh, 1986, Kingsland, 1991; Golley, 1996; NRC CIAE, 1996).

ii) A body of water is an island. Forbes' view fostered a focus on structure and processes within that islet rather than among islets. This internal focus was consistent with the ecosystem concept and remained wholly consistent with an assessment of limnology by limnologists in the 1990s (Lewis et al., 1995; Golley, 1996). One consequence is that limnology has been stranded apart from other disciplines that study natural systems (McIntosh, 1986; Hairston, 1990; Kalff, 1991; ASLO CLC, 1995; Golley, 1996; Brezonick, 1996).

iii) Results of studies within one aquatic system represent other such systems. Forbes (1887) organized his discussion by summarizing his observations among lakes according to lake type (e.g., floodplain lakes) and community (e.g., plankton). In doing so, he established a descriptive, typological approach to limnology that persists today.

Here I review the literature regarding the three points 
above. I begin with a commonly applied and broad definition of limnology as the study of inland waters. I later modify that definition. I also start with Ringelberg's (1993) distinction between ecosystem-oriented limnology and organism-oriented aquatic ecology: In ecology attention was and still is focussed on problems of individual organisms, populations and communities, thus on biological units at different integration levels. Consequently, ecology has always been an integral part of biology, which does not hold for limnology. Evolutionary thought, for instance, is central to ecology as it is in many other branches of biology. In contrast, limnology seems to manage to a large extent without Darwinian, evolutionary principles as is apparent from its textbooks. This distinction reflects other contemporary evaluations of limnology (Hairston, 1990; Kalff, 1991; ASLO CLC, 1995). I return to this distinction later, with some ideas about limnology's future. And because it remains especially important that a historical perspective be retained amidst our exponentially-increasing literature (Graham and Dayton, 2002), I cite below some vital reviews and historical landmarks in limnology and aquatic ecology.

\section{Is the ecosystem concept an organizing framework for limnology?}

"One of the best ways to understand the progress of freshwater science is to compare the textbooks of the past few decades."

S.R. Carpenter, foreword in Brönmark and Hansson

(1998)

If the ecosystem concept serves as an organizing framework for limnology, then most limnological textbooks should convey that organizational, hierarchical framework. Also, limnological research should be conducted in a holistic, integrative context, in which biota and their physicochemical environment are studied as an interactive system. To test the above hypotheses, I evaluated the tables of contents for limnology textbooks and recent peer-reviewed literature.

The ecosystem concept descended from Forbes' lakeas-a-microcosm is a popular organizing framework for limnology textbooks (Supplement 1). In addition, the Forbesian singular, internal view of aquatic systems is repeatedly emphasized in most texts. Of the 32 texts I examined, many provide a physical $(90 \%)$ and chemical (78\%) context (sometimes in great detail), followed by summaries of biotic assemblages (e.g., its biotic components, organized by habitat, taxon, or both). Interestingly, only 4 of 13 (31\%) texts published before 1990 include chapters on ecosystem ecology, whereas 14 of 19 (74\%) published since 1990 do so. Almost half (44\%) of texts also explain geological context, and applied limnology is included in over half $(56 \%)$ of the texts (Supplementary Tab. 1). In sum, limnology texts consistently follow Forbes' lead by describing internal components and interactions for a water body of a type, and ecosystem-scale processes are now commonly discussed in limnology texts. By comparison, relatively few texts evaluate heterogeneity and patterns among water bodies sufficiently to list that topic in a table of contents, and when they do, the content is always a small minority of content (Fig. 1A).

One symptom of an ecosystem-based approach in research would be a predominance of descriptive research rather than experimental approaches, as observed in Limnology \& Oceanography 1980-1990 (Bourget and Fortin, 1995). Also, keywords such as ecosystem ecology should be used at least as often as keywords representing subsystems (e.g., plankton, benthos or littoral) or concepts (e.g., population ecology or community ecology). Alternatively, most limnological research may now take a reductionist view, in which experimental ecology is more common than descriptive ecology, and subsystems (e.g., plankton) or targeted concepts (e.g., population ecology) are discussed more often than ecosystem ecology.

I searched the 1991-2012 journal literature in ISI Web of Science using the keywords aquatic OR freshwater in combination with three sets of other keywords: i) descriptive ecology or experimental ecology; ii) ecosystem ecology, plankton, benth*, or littoral; and iii) ecosystem ecology or community ecology or population ecology. I simply plotted the counts of papers identified with these keywords through time. I expected modern journal papers to be more often reductionist (i.e., report on subsystems or component species) and experimental. If so, then practicing limnology typically defers its integration to textbook authors but does not necessarily apply the ecosystem concept in practice. I expected this outcome for a combined influence of four reasons. First, a complete ecosystem study is a daunting task for any given investigator (or team) over multiple years (e.g., Likens, 1983; Schindler, 2006), especially in an era of specialization. Second, a comprehensive history $($ Golley,1996) discussed the wane of the ecosystem concept in favor of reductionist approaches that have enabled conceptual connections across habitats (e.g., trophic interactions, adaptation, and phenotypic plasticity). This potential generality for any one topic has great appeal, though it differs from classic, holistic limnology that dwells in a singular body of water (Ringelberg, 1993; Brezonick, 1996; Lampert, 1997). Third, I expected limnologists have responded much like other disciplines to the unabated combination of a publish-or-perish approach and indolent accounting of scientific merit in academia (Fischer et al., 2012). I expected this process would select against a comprehensive ecosystem analysis that counts as one paper, when an investigator might generate multiple least publishable units (LPUs; Broad, 1981) from the same data set. Of course, multiple 
papers on subsystems may eventually lead to an integrative overview paper for an especially compelling body of work (e.g., Likens, 1983), but my first and second expectations reinforce the third. Finally, I expected that a reductionist approach is now entrenched generationally, where students of aquatic community or population ecologists are more likely to themselves conduct aquatic community or population ecology without considering their work reductionistic relative to molecular biology, etc. They are correct, but overall reductionism may still be at work.

The integrative ecosystem approach to inland waters presented in most texts is remarkably unaligned with the majority of our research practice. As practiced in journal publications, limnology is almost fully replaced by aquatic ecology (sensu Ringelberg, 1993), in that experimental approaches greatly outnumber the descriptive (Fig. 1B) and far more studies are conducted on subsystems (e.g., populations, assemblages; Fig. 1C) or habitats (Fig. 1D) than on entire, integrative freshwater ecosystems. The results of my simple analyses of research literature and textbooks are consistent with my four expectations (above), though not a direct test of those expectations. At the least, there is a strong mismatch between how limnology is taught and how it is conducted. I must conclude that the ecosystem concept is an organizing framework for the teaching of limnology, but not for the conduct of it in practice.

What might this mean for limnology (sensu Ringelberg, 1993)? I think his characterization was accurate at the time, but that the difference between limnology and aquatic ecology in practice has since blurred; limnology is now equal to aquatic ecology, and distinctions of two decades ago no longer exist. If ecology is the interaction of organisms and their environment, then studies of the geomorphology, physics, and chemistry of aquatic ecosystems are nested within aquatic ecology and fully justifiable in their own scope, in the same way that studies of aquatic biota in vitro or in silico are part of aquatic ecol-
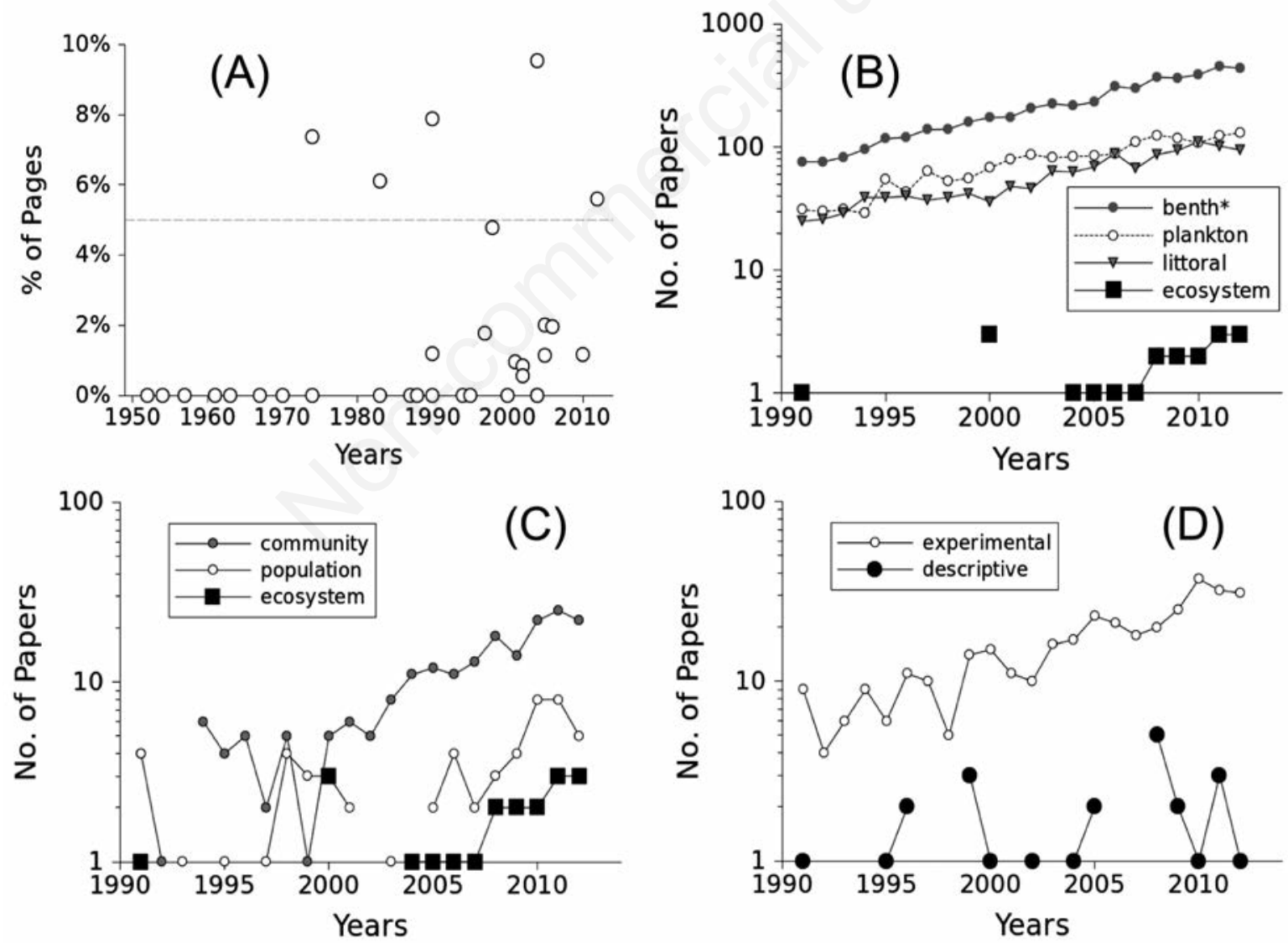

Fig. 1. Trends in limnology textbooks and peer-reviewed journals. Note that axes change among graphs and an exponential upward trend is expected. A) The estimated proportion of textbook pages dedicated to among-system patterns. More than $95 \%$ of texts typically focus within systems. B) Studies representing habitats relative to whole ecosystems. Benth* includes benthic and benthos. C) Studies representing component concepts relative to whole ecosystems. D) Studies using experimental and descriptive approaches in inland waters. Some trend lines are interrupted because values of zero cannot be plotted on a log scale. 
ogy. If ecology includes hierarchical levels of organization from individuals to the biosphere, then limnology is wholly consistent for a set of Earth's habitats. If limnology was formerly targeted to the ecosystem level, it is now practiced at multiple hierarchical levels that ultimately integrate to the ecosystem. I see no reason now to maintain a distinction between limnology and aquatic ecology, and suggest that limnology be defined simply as the ecology of inland waters. I return to this theme in the last portion of this paper.

\section{Are lakes and rivers like islands?}

"The great intellectual fascination of limnology lies in the comparative study of a great number of systems, each having some resemblance to the others and also many differences. Such a point of view presupposes that each lake can in fact be treated as at least a partly isolated system."

\section{G.E. Hutchinson (1964)}

The idea that a lake is like an island has been a common refrain (e.g., Maguire, 1963; Hutchinson, 1964; Keddy, 1976; Fryer, 1996; Dodson, 1992; Arnott et al., 2007). To be clear, an island-like system should be relatively isolated (i.e., more closed to biotic exchange than other systems) and relatively independent. To test the veracity of this metaphor we must consider patterns among systems and different kinds of systems, which differs markedly from the Forbesian within-system view.

A common analytical tool from island biogeography is a species-area relationship (SAR), which evaluates the number of species as a function of the habitat areas. A SAR is now considered one of the laws of ecology because SARs describe many fragmented sets of habitats, ranging from individual thistle plants to continents (MacArthur and Wilson, 1967; Brown, 1971; Schoener, 1976; Connor and McCoy, 1979; Ceballos and Brown, 1995). Because SARs are so common, a positively-sloped SAR with a high $\mathrm{r}^{2}$ is not by itself definitive evidence of an island-like system (Connor and McCoy, 1979; Lomolino, 1989), though that inference is common in lakeas-island papers. Instead, I reasoned that if lakes and rivers are biotically analogous to islands, then lakes, rivers, and islands should be quantitatively similar in their SAR parameters. One may expect that lakes and rivers have already been quantitatively compared to islands (I did). In fact, the island metaphor inherited from Forbes (1887) is typically presumed; area and other factors are then analyzed as predictors of species richness without quantitative comparison to islands (e.g., Barbour and Brown, 1974; Connor and McCoy, 1979; Browne, 1981; Eadie et al., 1986; Hugueny, 1989; Dodson, 1992; Oertli et al., 2002; Stomp et al., 2011). This approach reveals interesting pattern but does not actually test the island- like nature of lakes or rivers because SARs are so general (Schoener, 1976; Connor and McCoy, 1979; Lomolino, 1989). Here I analyzed SARs among lakes, rivers, and islands using appropriate regression techniques and then statistically compared regressions.

As one of the most widely discussed relationships in ecology and biogeography, the SAR literature is vast beyond the scope of this paper. I did not directly explore other factors (e.g., isolation, latitude, disturbance regimes, etc.) that may also affect species richness, though isolation effects can be inferred because SARs for more remote archipelagos have a lower intercept and a greater slope (Rosenzweig, 1995). Nor did I attempt to analyze for mechanisms (e.g., area-per-se, habitat heterogeneity, passive sampling, speciation) that have been proposed to explain SARs. As before, I expected that a sufficient number of values may represent actual patterns, but did not expect to obtain all values ever published. In addition, the long history of SAR research has generated much data without also adhering to analytical advances. As a result, technical problems arise but are not often addressed; perhaps these devils in the developing details are why I could find no quantitative comparison of SARs for lakes, rivers and islands using appropriate models.

A SAR is classically modeled as the power equation $\mathrm{S}=c \mathrm{~A}^{z}$, where $\mathrm{S}$ is species richness, and $c$ and $z$ are coefficients. The power equation is infrequently applied; instead a SAR is sometimes modeled as a semi-log equation (e.g., Drakare et al., 2006) but far more commonly modeled using log-transformed data, in an ordinary least squares (OLS) linear regression; $\log _{10}(\mathrm{~S})=\log _{10}(c)+z\left(\log _{10}\right.$ A). Four problems arise to date:

1. OLS regression is actually designed to predict $\mathrm{S}$ given a specific A, in contrast to the purpose of SAR analyses - to describe the true relationship between all values of $\mathrm{A}$ and $\mathrm{S}$. Evidence of the more general goal is the common practice of reporting $z$ coefficients relative to a canonical (i.e., general) value (Rosenzweig, 1995).

2. OLS regressions of SARs assume areas have no variance, when in fact, areas of lakes, watersheds, islands and most habitats are estimates with error (Connor and McCoy, 1979). This is especially apparent when one considers scale-dependence of coastline estimates (Mandelbrot 1983).

3. Though both the $c$ and $z$ coefficients affect the SAR shape (Lomolino, 1989), most studies only report and compare obtained $z$ coefficients obtained by OLS regression (e.g., Rosenzweig, 1995; Drakare et al., 2006). The $z$ coefficients are not affected by the various units of area used among studies, but area units strongly affect the $c$ coefficient. Thus, area must be standardized among studies to analyze and report both $c$ and $z$ coefficients.

4. A regression of $\log _{10}(\mathrm{~S})=\log _{10}(c)+z\left(\log _{10} \mathrm{~A}\right)$ applies a 
multiplicative error term and may not be the best fit (Xiao et al., 2011).

As a result of the above complications, a simple tally of reported SAR regression coefficients is not sufficient to compare lakes, rivers, and islands. Instead, I computed SARs using standardized major axis (SMA) regression to resolve problems 1-3 above. SMA regression is also known as model II, geometric mean, or reduced major axis regression [but see Warton et al. (2006) on why these terms are inappropriate] and can obtain results that are substantially different from OLS regressions (Connor and McCoy, 1979; Eadie et al., 1986; Warton et al., 2006). Unfortunately, many papers do not provide original data and I found that SMA regression coefficients cannot be reliably estimated from reported OLS values, despite conversion formulae provided by Connor and McCoy (1979). I retained the log-log equation in (last point above) because it is so common in the literature and generally sufficient (Xiao et al., 2011); results here should relate to the long history of SAR research and represent general comparisons among lentic and lotic systems and islands.

I gathered data in the literature for area and species richness among lentic and lotic systems and islands. I made no distinctions based on system size (e.g., lakes $v s$ ponds, rivers $v s$ streams). I limited analyses to fishes in aquatic systems and nonvolant mammals on islands. Among the limited reasonable choices (e.g., phytoplankton data exist for lakes (Stomp et al., 2011) but not for islands), I expected fishes and nonvolant mammals to be most comparable in dispersal among habitats and welldocumented. To check that comparability, I first compared the body mass - maximum dispersal distance regressions for fish $(\mathrm{N}=73)$ and nonvolant mammals $(\mathrm{N}=81)$ from data collected for Jenkins et al. (2007). The SMA regressions were not significantly different for slope $(\mathrm{P}=0.09)$ and intercepts broadly overlapped in $95 \%$ confidence intervals. I concluded that macroecological comparisons of fishes in lakes and rivers relative to mammals on islands may be fair for species-area relationships.

Positive and significant SARs have been observed among sites within a system (e.g., Angermeier and Schlosser, 1989; Oberdorff et al., 1993), but I omitted such studies to avoid confounding results with amongsystem analyses. I distinguished between oceanic and landbridge islands because they differ in SARs (Lomolino et al., 2010); thus I tested a subsidiary hypothesis that if lentic and lotic systems are like islands, then they would match more closely with landbridge islands than oceanic islands because oceanic islands are more isolated. Alternatively, lentic and/or lotic systems may more closely resemble continental habitat patches by having lesser $z$ coefficients but a greater $c$ coefficient than islands (i.e., be displaced above island SARs; MacArthur and Wilson, 1967; Rosenzweig, 1995). I also compared SARs for lentic and lotic systems and oceanic and landbridge islands within the Nearctic biogeographic realm (Holt et al., 2013; Lomolino et al., 2010), which was the only realm for which I could obtain data for all four types of systems. Preston (1960) also analyzed Nearctic SARs, but surprisingly, biogeographic spatial units are rarely used in SAR analyses. In sum, I conducted hierarchical tests of SARs: i) all inland waters $v s$ all islands; ii) global lentic systems, lotic systems, landbridge islands, and oceanic islands; and iii) Nearctic lentic systems, lotic systems, landbridge islands, and oceanic islands. I standardized area estimates to $\mathrm{km}^{2}$, and calculated SMA regressions of the equation $\log _{10}(\mathrm{~S})=\log _{10}(c)+z\left(\log _{10} \mathrm{~A}\right)$ with the smatr 3 package in $\mathrm{R}$ 2.14.1 (Warton et al., 2012; R Core Team, 2013), including tests of common $z$ coefficients among lakes, rivers, and continental and oceanic islands. The $c$ coefficients reported here were calculated as the antilog of $\log _{10}(c)$ solved for in regressions. I applied the Huber M estimator for robust regression estimates given that some data sets had outliers, and error variance was not necessarily homogeneous (Taskinen and Warton, 2011). I also applied Sidak corrections to $\mathrm{P}$ values based on multiple comparisons. Species and area data were obtained from the literature for 187 lentic systems, 88 lotic systems, 296 landbridge islands, and 96 oceanic islands (Tab. 1). In general, SMA regressions obtained strong fits to data; $\mathrm{r}^{2}$ values ranged from 0.37 to 0.83 , mean $r^{2}=0.58$. For nine of ten SARs estimated here, the simple relationship with area explained about one half or more of the variance in species richness, meaning that other factors (e.g., isolation, latitude, disturbance) are often secondary.

Globally, the SAR of freshwater systems was significantly different $(\mathrm{P}<<0.0001)$ from that of islands; freshwater systems had a much greater $\mathrm{c}$ coefficient but a lower $\mathrm{z}$ coefficient than islands (Tab. 1, Fig. 2A). Thus, global lentic and lotic systems are more consistent with continental habitat patches and are not equivalent to islands, likely related to greater island isolation (MacArthur and Wilson, 1967; Rosenzweig, 1995). At the next level of detail, lentic systems were not equivalent to lotic systems (Tab. 1, Fig. 2B). Likewise, pair-wise comparisons among global lentic systems, lotic systems, landbridge islands, and oceanic islands were all significantly different $(\mathrm{P} \leq 0.05)$ except for the $z$ coefficients of rivers and oceanic islands (Tab. 1). That similarity is not sufficient to consider river SARs analogous to those of oceanic islands because $c$ coefficients also affect SAR shape (Lomolino, 2000) and those were again very different (Tab. 1, Fig. 2B). Finally, patterns among Nearctic lentic and lotic systems, landbridge islands, and oceanic islands were generally similar to global patterns (compare Figs. 2B and 2C), but details differed importantly for statistical tests of regressions. Nearctic lentic and lotic systems had $z$ coefficients that were not significantly different from landbridge is- 
lands, though $c$ coefficients were very different (Tab. 1, Fig. 2C). All other pairwise comparisons were significantly different $(\mathrm{P} \leq 0.05)$.

Is a lake or river like an island? At all levels examined here, I must answer no. Instead, the SAR patterns for lentic and lotic systems are more similar to expectations for continental habitat patches than for islands (MacArthur and Wilson, 1967; Rosenzweig, 1995). Lakes and islands may share similar $z$ coefficients, but this alone is not sufficient to claim equivalence because $c$ coefficients differ markedly (Lomolino, 1989). Based on these analyses of fish and mammal SARs, there is no basis to consider lentic and lotic systems as islands. These results appear roughly consistent with those of Drakare et al. (2006), though their analyses were subject to problems 1-3 (above).

My conclusion carries several caveats and implications. First, fish and mammals may not be equivalent for the purpose of SARs and this difference may underlie the results, rather than the habitats. I addressed this possibility (above), but that potential complaint begs the question - if not these taxa, what can be used to fairly compare lakes and rivers to islands? Few other options exist because matching taxa do not exist in large numbers in both aquatic and terrestrial habitats, or because not enough data sets exist, or both. Thus, this potential complaint only adds to my conclusion - evidence to consider lakes as islands is wanting and will likely continue to remain so. It is worth reiterating that the mere presence of a SAR is not sufficient evidence that a set of habitats are islands (Connor and McCoy, 1979). Instead, analyses here differ from most prior work by using SMA regressions to statistically compare $c$ and $z$ coefficients of SARs among different systems. Also, it has been common practice to evaluate and report only $z$ coefficients in SARs, though $c$ coefficients affect SAR shape and vary more widely than $z$ coefficients (Lomolino, 1989). Both coefficients need to be reported and analyzed with SMA regressions. This statement indicates that we still have much to learn about SARs among systems. In addition, biogeographic units (e.g., the Nearctic) should be more commonly considered in limnological analyses. Future analyses for other biogeographic realms may differ in the details, but analyses presented here show that the comparison of lentic

Tab. 1. Summary of species-area relationships for fishes in lakes and rivers and for mammals on landbridge and oceanic islands. Standardized major axis (SMA) regressions were computed for the equation $\log _{10}($ species richness $)=\log (\mathrm{c})+\mathrm{z}^{*} \log _{10}(\operatorname{area})$.

\begin{tabular}{|c|c|c|c|c|c|c|}
\hline Comparisons & $\begin{array}{l}\text { Prob. of no overall } \\
\quad \text { difference in } z\end{array}$ & Modeled systems & $c( \pm 95 \% \mathrm{CI})$ & $z( \pm 95 \% \mathrm{CI})$ & $r^{2}$ & $\mathrm{~N}$ \\
\hline \multirow[t]{2}{*}{$\begin{array}{l}\text { Global (lentic and lotic systems }= \\
v s \text { all islands }=\text { ) }\end{array}$} & $\mathrm{P}<<0.0001$ & Lentic and lotic systems & $\begin{array}{l}10.179 \\
(1.010)\end{array}$ & $\begin{array}{c}0.20280 \\
(0.01213)\end{array}$ & 0.66 & 275 \\
\hline & & Islands & $\begin{array}{c}0.765 \\
(1.134)\end{array}$ & $\begin{array}{c}0.34393 \\
(0.02399)\end{array}$ & 0.48 & 392 \\
\hline \multirow[t]{4}{*}{$\begin{array}{l}\text { Global lentic systems } v s \text { lotic systems } \\
v s \text { landbridge islands } v s \text { oceanic islands }{ }^{\circ}\end{array}$} & $\mathrm{P}<<0.0001$ & Lentic systems & $\begin{array}{l}10.571 \\
(1.117)\end{array}$ & $\begin{array}{c}0.19865 \\
(0.02021)\end{array}$ & 0.50 & 187 \\
\hline & & Lotic systems & $\begin{array}{c}3.879 \\
(1.505)\end{array}$ & $\begin{array}{c}0.30365 \\
(0.04096)\end{array}$ & 0.69 & 88 \\
\hline & & Landbridge islands & $\begin{array}{c}0.801 \\
(1.131)\end{array}$ & $\begin{array}{c}0.38273 \\
(0.02595)\end{array}$ & 0.64 & 296 \\
\hline & & Oceanic islands & $\begin{array}{c}0.525 \\
(1.386)\end{array}$ & $\begin{array}{c}0.28744 \\
(0.04558)\end{array}$ & 0.37 & 96 \\
\hline \multirow[t]{4}{*}{$\begin{array}{l}\text { Nearctic lentic systems } v s \text { lotic systems } \\
v s \text { landbridge islands } v s \text { oceanic islands }\end{array}$} & $\mathrm{P}=0.0002$ & Lentic systems & $\begin{array}{l}11.832 \\
(1.114)\end{array}$ & $\begin{array}{c}0.25046 \\
(0.02980)\end{array}$ & 0.50 & 147 \\
\hline & & Lotic systems & $\begin{array}{c}3.962 \\
(1.504)\end{array}$ & $\begin{array}{c}0.34800 \\
(0.04729)\end{array}$ & 0.83 & 38 \\
\hline & & Landbridge islands & $\begin{array}{c}1.083 \\
(1.157)\end{array}$ & $\begin{array}{c}0.29220 \\
(0.03193)\end{array}$ & 0.60 & 94 \\
\hline & & Oceanic islands & $\begin{array}{c}1.026 \\
(1.205)\end{array}$ & $\begin{array}{c}0.18435 \\
(0.04471)\end{array}$ & 0.54 & 26 \\
\hline
\end{tabular}

${ }^{\circ}$ Global rivers and oceanic islands were not significantly different $(P=0.997)$ for $\mathrm{z}$ coefficients but had significantly different $\mathrm{c}$ coefficients (as judged by $95 \%$ confidence intervals). All other pairwise comparisons were significant $(P<0.05) .{ }^{*}$ Nearctic lakes and rivers were not significantly different for $\mathrm{z}$ coefficients from landbridge islands $(P=0.364$ and 0.305 , respectively). Nearctic lake $\mathrm{z}$ coefficients were also not significantly different from oceanic islands $(P=0.256)$. All other pairwise comparisons were significant $(P<0.05)$. 
and lotic systems to islands should be considered no more than a poetic metaphor (as in all the world's a stage); the comparison breaks down upon closer inspection. Instead, it is more appropriate to think of freshwater systems as being comparable to terrestrial habitat patches in their isolation. As a result, limnology is not so far afield from terrestrial ecology.

\section{Are lentic and lotic systems replicates?}

"A group of lakes confronts the investigator as a series of very complex physicochemical and biological systems, each member of which has its own characteristics and yet also has much in common with the other members of the group."

G.E. Hutchinson (1957), pg. 1

Forbes' (1887) lake-as-a-microcosm view emphasized research on a lake's characteristics that implicitly informs us about other lakes of the same type. This approach thus assumes lakes are, in part, independent replicates of a type. This view has persisted for nearly a century, as evidenced by the typological approach in limnology textbooks (Supplementary Tab. 1) and Hutchinson's encyclopedic Treatise on Limnology series (Hutchinson, 1957, 1967). Why did Forbes' categorical, deterministic view of lakes persist uncontested for about a century, while a colleague (Gleason, 1926) contested the same fundamental idea applied to terrestrial vegetation (Clements, 1916)? Is it because limnologists inherited the concept of lakes as being at least partly isolated, independent islets (to fuse the phrases of quoted Forbes and Hutchinson above)? Is it because organisms below the waterline are more removed from our direct observation than terrestrial vegetation? To my knowledge, limnology has followed ecology's lead in its recognition that both stochastic regional processes and deterministic local processes contribute to heterogeneity among inland waters (e.g., Ricklefs, 1987; Jenkins, 1995; Jenkins and Buikema, 1998; Bohonak and Jenkins, 2003). Multiple studies now try to resolve regional (i.e., dispersal) and local processes controlling various aquatic ecosystems (e.g., Angermeier and Winston, 1998; Cottenie and De Meester, 2004).

Of course, others have questioned the typology of lakes that extends from the singular, internal focus inherited from Forbes. For example, Lindeman's famous paper on the trophic-dynamic concept (Lindeman 1942) was initially rejected, in part because Chancey Juday doubted the generality of the single-system view; "According to our experiences, lakes are rank individualists and are very stubborn about fitting mathematical formulae and artificial schemes proposed by man" (emphasis by Juday; Cook, 1977). Lindeman's paper eventually served as a conceptual foundation for much of ecosystem ecology and Juday's initial concern on lake individuality does not ap- pear to have resurfaced explicitly. However, no-one expects that lakes or rivers are identical; instead, we know that they vary as a result of latitude, landscape position, drainage basin conditions, climate, morphometry, history, etc. This set of relationships is the basis for comparative limnology, which seeks to infer underlying causes of pat-

(A)

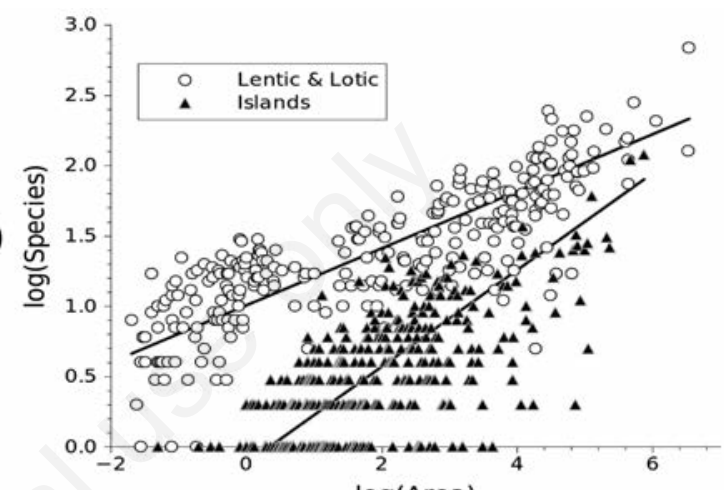

(B)

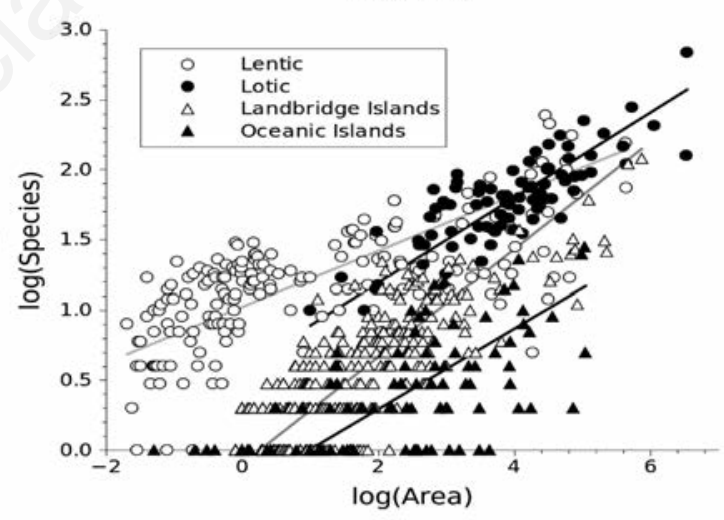

(C)

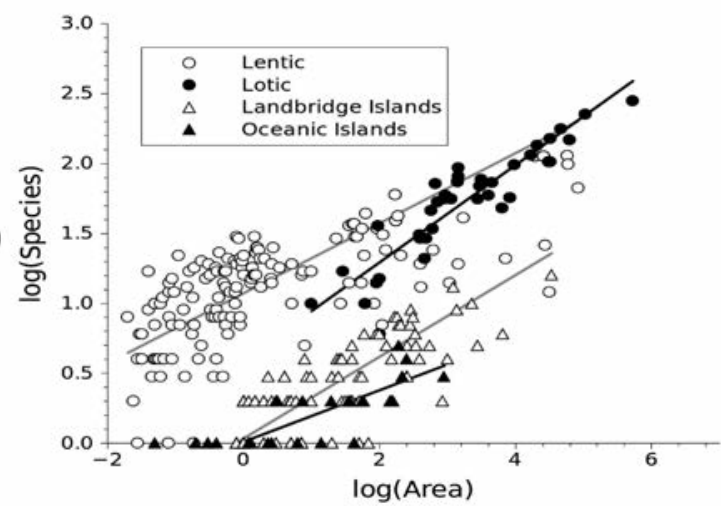

Fig. 2. Species-area relationships for A) [global lakes and rivers] relative to [global islands]; B) each of global lakes, rivers, landbridge islands and oceanic islands; and C) each of lakes, rivers, landbridge islands and oceanic islands in the Nearctic realm. See Tab. 1 for regression details. 
terns among lentic or lotic systems (e.g., Kratz and Frost, 2000; Wetzel, 2001). Instead of absolute replicability, I tested here for relative replicability by asking Are lentic and lotic systems more replicable than terrestrial systems?

I used beta diversity $(\beta)$ as a measure of differences among various assemblages in lakes and rivers relative to those among terrestrial systems. Beta diversity measures are themselves quite diverse and debated, and the effects of different measures and scaling effects remain unknown (e.g., Koleff et al., 2003; Tuomisto, 2006; Baselga, 2010; Anderson et al., 2010). Instead, I merely summarized an array of analyses and meta-analyses already conducted on $\beta$ patterns, with the logic that repeated patterns by different measures will indicate generality. I emphasized distance-decay in similarity to compare among lentic, lotic, and terrestrial systems (Nekola and White, 1999; Soininen et al., 2007). Distance decay in similarity is also described as spatial autocorrelation or beta diversity and is considered another law (Nekola and White, 1999). As above for SARs, salient questions then center on the general shape of the relationship (Fig. 3) rather than whether one exists. A diversity of similarity (or dissimilarity) measures have been studied by different sampling methods and at diverse spatial scales. As a result, equilibration of measures and quantitative evaluation of slopes and goodness of fit measures are not reliable (Koleff et al., 2003; Steinbauer et al., 2012). Instead, I simply collected distance decay studies in the literature and recorded the general shape of the distance decay in similarity (Fig. 3) obtained if axes units were untransformed. I selected data sets that included multiple drainage basins to avoid confounding comparisons among and within systems. Also, I selected studies that used simple regressions of classic similarity measures and distance in order to capture more studies and maximize comparability.

Assemblage similarity may occur across distance in one of four general shapes. Similarity among assemblages may not significantly decay with distance (i.e., zero slope; Fig. 3A), but this is most likely due to a weak pattern (i.e., low $\mathrm{r}^{2}$ ) than to a strong pattern (i.e., high $\mathrm{r}^{2}$ ) across all dis- tances. Alternatively, decay in similarity may be deferred to larger distances, so that assemblages at local to intermediate distances may be considered replicable up to a threshold, beyond which they rapidly become more different (Fig. 3B) or concave function of distance (Fig. 3D). Given that distance decay in similarity should be common, I hypothesized that lentic, lotic, and terrestrial systems should most commonly exhibit curves $\mathrm{C}$ or $\mathrm{D}$, and that they should do so in similar proportions if they are all similar in replicability. I obtained 66 distance-decay relationships from the peer-reviewed literature (20 lentic systems, 20 lotic systems, 26 terrestrial systems). By far, concave decay curves (Fig. 3D) were most common among all systems (34 of 66 cases, or 52\%), followed by linear decays ( 23 cases; $35 \%$ ) and no significant decay $(9$

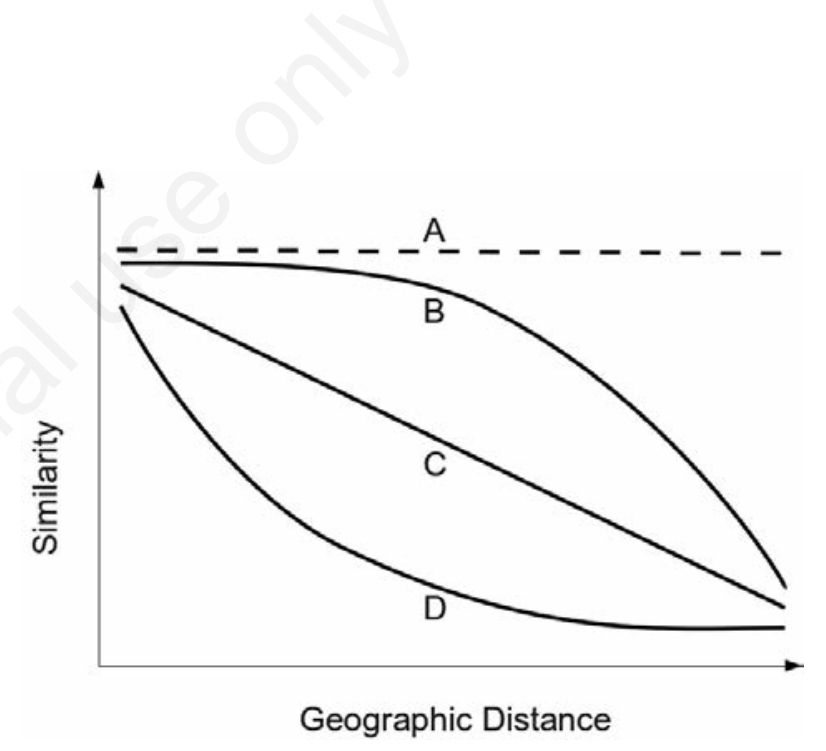

Fig. 3. Potential curve shapes of distance decay in similarity. A) An unlikely and generally high similarity across all distances would indicate inland waters are uniform replicates. B) A convex curve would indicate inland waters are replicates of spatial neighborhoods. More likely curves are: C) a linear or D) concave decay in similarity with distance, given general expectations (Nekola and White, 1999).

Tab. 2. Number (and percent) of studies among lentic, lotic, and terrestrial systems that reported a distance decay curve shape that had a nonsignificant decay (A), a convex curve (B), a linear decay (C), or a concave curve (D; also see Fig. 3). In order to standardize among studies, shapes were interpreted as untransformed axes in the relationship between geographic distance and similarity.

\begin{tabular}{lcccc}
\hline Curves & Lakes & Rivers & Terrestrial & Total \\
\hline $\mathrm{A}^{\circ}$ & $4(20 \%)$ & $4(20 \%)$ & $1(4 \%)$ & $9(13 \%)$ \\
$\mathrm{B}$ & $0(0 \%)$ & $0(0 \%)$ & $0(0 \%)$ & $0(0 \%)$ \\
$\mathrm{C}$ & $8(40 \%)$ & $4(20 \%)$ & $11(42 \%)$ & $23(35 \%)$ \\
$\mathrm{D}$ & $8(40 \%)$ & $12(60 \%)$ & $14(54 \%)$ & $34(52 \%)$ \\
Total & 20 & 20 & 26 & 66 \\
\hline
\end{tabular}

${ }^{\circ}$ All data sets classified as shape A had low $r^{2}$ values (see Supplementary Tab. 2) and thus do not indicate high replicability across distance as suggested in Fig. 3. 
cases; 14\%; Tab. 2). No cases were observed with a convex curve (Fig. 3B), consistent with a general absence of local to regional replicability or a threshold effect. I retained additional information for each data set (where possible) for further analyses (Supplementary Tab. 2).

I tested the hypothesis that lentic, lotic, and terrestrial systems have similar distance decay relationships using Fisher's exact tests. The systems differed overall in their proportions of curve shapes $(\mathrm{P}<0.001)$, due to differences between all pairs of lakes, rivers, and terrestrial systems (all $\mathrm{P}<0.05$ ), including the difference between aquatic and terrestrial systems $(\mathrm{P}=0.01 ;$ Tab. 2). To better understand why these differences existed, I conducted a backward, stepwise model selection approach using stepAIC (in the MASS package; R Core Team, 2013), starting with a full factorial linear model of all variables obtained in Supplementary Tab. 2. Only spatial extent significantly $(\mathrm{P}=0.003)$ predicted model shape, and the stepwise AIC approach retained the correlated variables of spatial extent, number of taxa, and number of sites. In addition, spatial extent significantly $(\mathrm{P}=0.0002)$ varied among lentic, lotic, and terrestrial systems, where terrestrial systems were studied at far greater spatial extent than aquatic systems (Fig. 4).

In summary, lentic and lotic systems are not more replicable than terrestrial systems, and distance decay in similarity is a rule for lentic, lotic and terrestrial systems. However, lentic and lotic systems differ from terrestrial systems in the mix of distance decay relationships, where aquatic systems have a greater proportion of exceptions to the rule, related to smaller spatial scales of studies than among terrestrial systems. The few exceptions to the rule in aquatic systems do not indicate replicability because

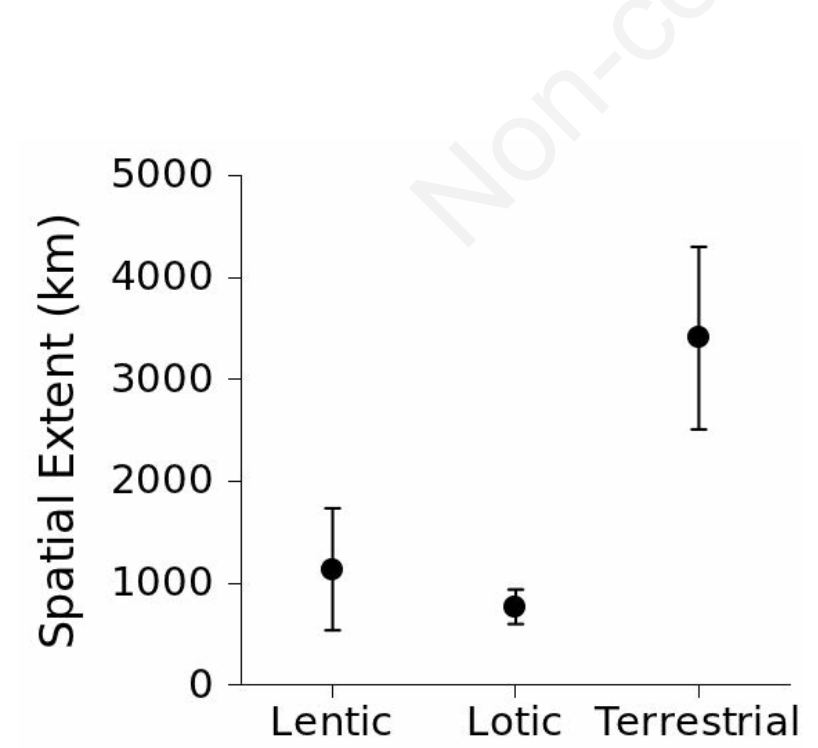

Fig. 4. Mean spatial extent of lentic $(\mathrm{N}=20)$, lotic $(\mathrm{N}=18)$, and terrestrial $(\mathrm{N}=15)$ studies on distance decay of similarity. Error bars are $95 \%$ confidence intervals. $\mathrm{N}$ differs here from Tab. 2 because some studies did not report spatial extent. distance decay in similarity was highly variable (low $\left.\mathrm{r}^{2}\right)$, indicating substantial variance among systems that is related to something other than simple distance measures.

\section{A plural view}

"Studies of individual lakes have provided important insights into numerous basic limnological processes. For general understanding, however, limnologists must incorporate a comparative perspective that considers the diversity of conditions that occur across a range of lakes and the factors that generate them."

T.K Kratz and T.M. Frost (2000)

The holistic, internal focus on singular aquatic ecosystems advocated by Forbes over a century ago was important to limnology and led to rich knowledge about the structure and function of aquatic ecosystems. Forbes' view remains important today but may also influence limnology in unrecognized ways. I outlined above three such influences: we teach a Forbesian view as an organizing paradigm but rarely practice its full breadth; we often think of aquatic systems as islands when they appear to be more like continental habitat patches; and aquatic systems are no more replicable than are terrestrial systems. Recent paradigms offered for limnology are consistent with Forbes' lake-asa-microcosm (ASLO CLC, 1995; Brezonick, 1996; Reynolds, 1998) or reflect expansion of that paradigm to include climate change (Walz and Adrian, 2008). Given that paradigms tend to evolve rather than shift wholesale (Graham and Dayton, 2002), I offer a modern conceptual model for limnology (Fig. 5) that attempts to maintain its continuity with the valuable research accrued to date while better connecting to current limnology as represented by papers in this volume. This model is based on three paradigms already in practice: the traditional lake-as-a-microcosm, multiple systems, and open systems. The intersections of these elements form the disciplines of comparative limnology, landscape limnology, and biogeographic limnology (Fig. 5). In combination, the three disciplines comprise a complete modern model of limnology.

Comparative limnology is a long-standing, plural form of limnology (Wetzel, 2001), without which analyses above could not have been conducted. The organization of lake districts fostered this approach (Kratz and Frost, 2000); other early examples, albeit on a small scale, include Brooks and Dodson (1965) and Dillon and Rigler (1974). Modern comparative limnology studies lakes-asplural-microcosms in the same way that other ecologists study patches across a landscape or latitudinal gradients in diversity. I simply argue here that we more explicitly and more often express that plural view, consistent with a more useful, modern definition of limnology as the ecology of inland waters. This shift to a plural view does not mean limnologists have abandoned a detailed study of a 
system, but instead means that single-system research connects to other systems in concept and evidence. This is all the more possible with technological advances, including informatic approaches. Regional examples of limno-informatic efforts include a Long Term Ecological Research site (http://lter.limnology.wisc.edu/datacatalog/ search) and the CSI Limnology project (http://csilimno. cse.msu.edu) - more such efforts are needed and would be all the more valuable if connected in a global database (e.g., the Global Biodiversity Information Facility; http://data.gbif.org).

In addition, limnology now often studies inland waters as open systems (Fig. 5), meaning that the relative importance of the exchange of organisms, materials and energy among systems is of interest. For lack of an already established name, I call this discipline landscape limnology because it is related to landscape genetics (Manel et al.,
2003) and occurs within the context of landscape connectivity, including interactions with terrestrial systems. An important part of this work is research about metapopulation, metacommunity, and meta-ecosystem concepts (e.g., Gotelli and Taylor, 1999; Forbes and Chase, 2002; Howeth and Leibold, 2008; Cottenie et al., 2003; Van de Meutter et al., 2007; Larned et al., 2010, some papers in this volume).

Finally, limnology also takes a biogeographic approach (Fig. 5), in which it evaluates the interactions among multiple freshwater systems in space and time, including the effects of: the histories of plate tectonics, glaciation, and human resource use; isolation; and latitudinal and altitudinal gradients (e.g., Walker and Mathewes, 1989; France, 1992; Schindler et al., 1996; Koskinen et al., 2002; Schumm et al., 2000; Scheffer et al., 2006; Smol, 2008). A greater and more explicit recog-

\section{Landscape Limnology: Exchange of materials, energy, and organisms in an inland water and with its landscape}
Complete Limnology: Historical, internal and external drivers of inland waters structure and function

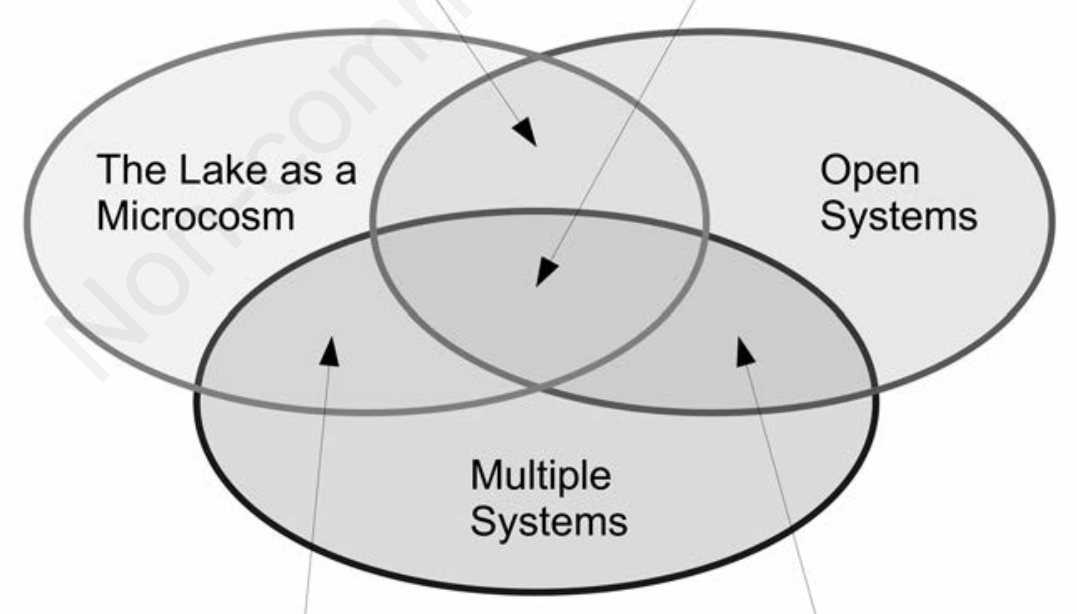

\section{Comparative Limnology: Patterns among and within inland waters and the correlates that may explain those patterns}

\section{Biogeographic Limnology: Geography and history of organismal and material flux among inland waters}

Fig. 5. A graphical representation of modern limnology. Ellipses represent paradigms, including Forbes' Lake as a Microcosm (1887), which led to the ecosystem concept and represents limnology's traditional focus within a system. Open Systems studies evaluate exchanges of materials and energy (e.g., discharge, nutrient flux, allochthonous C), and organisms among systems. Multiple Systems evaluates spatial distributions and fundamental properties of inland waters (e.g., glacial moraine lakes, tidal rivers). Interactions of these three paradigms represent modern limnological disciplines (in boxes) which combine to make a complete limnology. 
nition of biogeography in limnology as it is taught and practiced will help limnology increase its relevance in the coming integration of ecology and biogeography (Ricklefs and Jenkins, 2011). If limnology more explicitly and widely recognizes these existing paradigms and disciplines as a foundation in limnology courses and research, it will more fully embrace a plural approach and become more fully related to studies of terrestrial and marine systems that also apply those conceptual frameworks (Fig. 6). Limnology has been internally-focused (Fig. 6A) and thus distinct from ecology and evolutionary biology for decades (Hairston, 1990; Ringelberg, 1993; ASLO CLC, 1995). To overcome this former segregation and gain broader relevance, limnology must continue to be more externally comparable (Fig. 6B) so results in lakes and rivers can be compared to those on land or in the oceans. For example, analyses presented here and comparing SARs and beta diversity among different kinds of inland waters, islands, and continental habitats appear to be far less common in the literature than analyses within each set. Comparisons within and among systems are needed (Fig. 6), but will not happen until limnology is conceptually linked to other disciplines in shared paradigms.

To conclude, I argue that limnology would do well to embrace a modern definition based on plurals: it is the

(A)

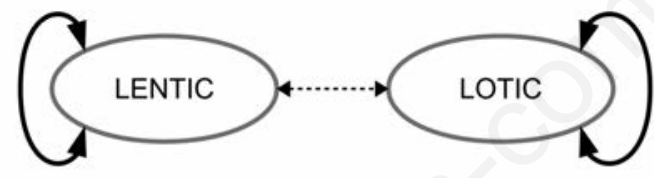

(B)

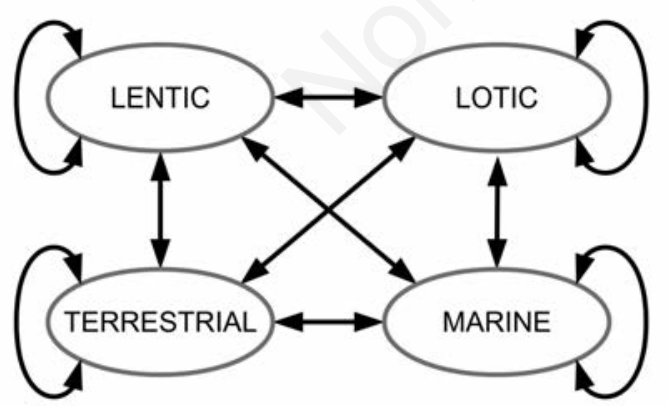

Fig. 6. Historical and potential approaches in limnology and beyond. A) Traditional limnology has historically focused within lentic systems or lotic systems (curved arrows) and has and rarely compared among lentic and lotic systems (thin dashed arrow); this made sense when the goal was to understand each of those systems. B) Future research may expand this view to maintain that historical approach while also comparing among lentic and lotic systems and terrestrial and marine systems (straight arrows); surprisingly, little progress has been made in this larger view. ecology of inland waters, including the study of physical, chemical, and biological attributes and interactions in aquatic environments. Modern limnology also seeks to understand the importance of evolution, geography and history among multiple, open systems for current and future ecological conditions. Limnology should continue to be more plural and less singular in its work, including comparisons among different types of inland waters and with terrestrial and marine ecosystems. To do so will require that we more explicitly recognize the long-lasting influence of Forbes' Lake as a Microcosm (1887) on our thinking, be prepared to expand our view beyond that century-old viewpoint, and thus make limnology even more relevant to science and society.

\section{ACKNOWLEDGMENTS}

I thank the editors of this special volume for the opportunity to write this paper and the reviewers for their comments that helped improve it. Leslie Real and James Brown included Forbes (1887) as the first paper in their excellent compendium - I thank them and many graduate students for the discussions that seeded the ideas expressed here. I am also grateful to the Ying Family Foundation for their continued support of my research.

\section{REFERENCES}

Anderson MJ, Crist TO, Chase JM, Vellend M, Inouye BD, Freestone AL, Sanders NJ, Cornell HV, Comita LV, Davies KF, Harrison SP, Kraft NJB, Stegen JC, Swenson NG, 2010. Navigating the multiple meanings of $\beta$ diversity: a roadmap for the practicing ecologist. Ecol. Lett. 14;19-28.

Angermeier PL, Schlosser IJ, 1989. Species-area relationship for stream fishes. Ecology 70:1450-1462.

Angermeier PL, Winston MR, 1998. Local vs. regional influences on local diversity in stream fish communities of Virginia. Ecology 79:911-927.

Arnott SE, Magnuson JJ, Dodson SI, Colby ACC, 2007. Lakes as islands: biodiversity, invasion, and extinction, p. 67-88. In: J.J. Magnuson, T.K. Kratz and B.J. Benson (eds.), Longterm dynamics of lakes in the landscape: long-term ecological research on north temperate lakes. Oxford University Press, Oxford.

ASLO CLC (Challenges for Limnology Committee), 1995. Challenges for limnology in the United States and Canada: an assessment of the discipline in the 1990's. Available from: http://www.aslo.org/bulletin/95_v4_i2.pdf

Barbour CD, Brown JH, 1974. Fish species diversity in lakes. Amer. Naturalist 108:473-489.

Baselga A, 2010. Multiplicative partition of true diversity yields independent alpha and beta components; additive partition does not. Ecology 91:1974-1981.

Bourget E, Fortin M-J, 1995. A commentary on current approaches in the aquatic sciences. Hydrobiologia 300/301:1-16.

Brezonick PL, 1996. Organizing paradigms for the study of inland water ecosystems. National Research Council (U.S.), 1996. Committee on Inland Aquatic Ecosystems. Freshwater 
ecosystems: revitalizing educational programs in limnology. National Academy Press, Washington.

Broad WJ, 1981. The publishing game: getting more for less. Science 211:1137-113.

Brönmark C, Hansson L-A, 1998. The biology of streams and rivers. Oxford University Press, Oxford: 304 pp.

Brooks JL, Dodson SI, 1965. Predation, body size, and composition of plankton. Science 150:28-35.

Brown JH, 1971. Mammals on mountaintops: nonequilibrium insular biogeography. Amer. Naturalist 105:467-478.

Browne RA, 1981. Lakes as islands: biogeographic distribution, turnover rates, and species composition in the lakes of central New York. J. Biogeogr. 8:75-83.

Ceballos G, Brown JH, 1995. Global patterns of mammalian diversity, endemism, and endangerment. Conserv. Biol. 9:559-568.

Clements FE, 1916. Plant succession: an analysis of the development of vegetation. Carnegie Institute of Washington: $658 \mathrm{pp}$.

Connor EF, McCoy ED, 1979. The statistics and biology of the species-area relationship. Am. Nat. 113:791-833.

Cook RE, 1977. Raymond Lindeman and trophic-dynamic concept in ecology. Science 198:22-26.

Cottenie K, De Meester L, 2004. Metacommunity structure: synergy of biotic interactions as selective agents and dispersal as fuel. Ecology 85:114-119.

Dillon PJ, Rigler FH, 1974. The phosphorus-chlorophyll relationship in lakes. Limnol. Oceanogr. 19:767-773.

Dodson SI, 2002. Predicting crustacean zooplankton species richness. Limnol. Oceanogr. 37:848-856.

Drakare S, Lennon JJ, Hillebrand H, 2006. The imprint of the geographical, evolutionary and ecological context on species-area relationships. Ecol. Lett. 9:215-227.

Eadie JM, Hurly TA, Montgomerie RD, Teather KL, 1986. lakes and rivers as islands: relationships in the fish faunas of Ontario. Environ. Biol. Fish. 15:81-89.

Fischer J, Ritchie EG, Hanspach J, 2012. Academia's obsession with quantity. Trends Ecol. Evol. 27:473-474.

Forbes SA, 1887. The lake as a microcosm. Bulletin of the Peoria Scientific Association, pp. 77-87.

Forbes AE, Chase JM, 2002. The role of habitat connectivity and landscape geometry in experimental zooplankton metacommunities. Oikos 96:433-440.

France R, 1992. The North American latitudinal gradient in species richness and geographical range of freshwater crayfish and amphipods. Am. Nat. 139:342-354.

Fryer G, 1996. Endemism, speciation, and adaptive radiation in great lakes. Environ. Biol. Fish. 45;109-131.

Gleason HA, 1926. The individualistic concept of the plant association. B. Torrey Bot. Club 53:7-26.

Golley FG, 1996. A history of the ecosystem concept in ecology: more than the sum of the parts. Yale University Press, New Haven: 254 pp.

Gotelli NJ, Taylor CM, 1999. Testing metapopulation models with stream-fish assemblages. Evol. Ecol. Res. 1:835-845.

Graham MH, Dayton PK, 2002. On the evolution of ecological ideas: paradigms and scientific progress. Ecology 83:14811489.

Hackney CT, Adams SM, Martin WH, 1992. Biodiversity of the southeastern United States. J. Wiley \& Sons, New York: $800 \mathrm{pp}$.
Hairston NG Jr., 1990. Problems with the perception of zooplankton research by colleagues outside aquatic sciences. Limnol. Oceanog. 35:1214-1216.

Hanksi I, 1999. Metapopulation ecology. Oxford University Press, Oxford: 313 pp.

Hasler AD, 1947. Eutrophication of lakes by domestic drainage. Ecology 28:383-395.

Holt BG, Lessard J-P, Borregaard MK, Fritz SA, Araújo MB, Dimitrov D, Fabre PH, Graham CH, Graves GR, Jønsson KA, Nogués-Bravo D, Wang Z, Whittaker RJ, Fjeldså J, Rahbek C, 2013. An update of Wallace's zoogeographic regions of the world. Science 339:74-78.

Holyoak M, Leibold MA, Holt RD, 2005. Metacommunities: spatial dynamics and ecological communities. University of Chicago Press: 520 pp.

Howeth JG, Leibold MA, 2008. Planktonic dispersal dampens temporal trophic cascades in pond metacommunities. Ecol. Lett. 11:245-257.

Hugueny B, 1989. West African rivers as biogeographic islands: species richness of fish communities. Oecologia 79:236-243.

Hutchinson GE, 1957. A treatise on limnology, vol. 1. J. Wiley \& Sons, New York: 1015 pp.

Hutchinson GE, 1967. A treatise on limnology, vol. 2. J. Wiley \& Sons, New York: $1115 \mathrm{pp}$.

Hutchinson GE, 1964. The lacustrine microcosm reconsidered. Am. Sci. 52:334-341.

Jenkins DG, 1995. Dispersal-limited zooplankton distribution and community composition in new ponds. Hydrobiologia 313/314:15-20.

Jenkins DG, Brescacin CR, Duxbury CV, Elliott JA, Evans JA, Grablow KR, Hillegass M, Lyon BN, Metzger GA, Olandese ML, Pepe D, Silvers GA, Suresch HN, Thompson TN, Trexler CM, Williams GE, Williams NC, Williams SE, 2007. Does size matter for dispersal distance? Global Ecol. Biogeogr. 16:415-425.

Jenkins DG, Buikema AL Jr., 1998. Do similar communities develop in similar sites? A test with zooplankton structure and function. Ecol. Monogr. 68:421-443.

Kalff J, 1991. On the teaching and funding of limnology. Limnol. Oceanog. 36:1499-1501.

Keddy PA, 1976. Lakes as islands: the distributional ecology of two aquatic plants, Lemna minor L. and L. trisulca L. Ecology 57:353-359.

Kingsland SE, 1991. Defining ecology as a science, p. 1-13. In: L.A. Real and J.H Brown (eds.), Foundations of ecology: classic papers with commentaries. University of Chicago Press, Chicago.

Koleff P, Gaston KJ, Lennon JJ, 2003. Measuring beta diversity for presence-absence data. J. Anim. Ecol. 72:367-382.

Koskinen MT, Knizhin I, Primmer CR, Schlötterer C, Weiss S, 2002. Mitochondrial and nuclear DNA phylogeography of Thymallus spp. (grayling) provides evidence of ice-age mediated environmental perturbations in the world's oldest body of fresh water, Lake Baikal. Mol. Ecol. 11: 2599-2611.

Kratz TK, Fros TM, 2000. The ecological organisation of lake districts: general introduction. Freshwater Biol. 43:297-299.

Lampert W, 1997. Zooplankton research: the contribution of limnology to general ecological paradigms. Aquat. Ecol. 31:19-27. 
Larned ST, Datry T, Arscott DB, Tockner K, 2010. Emerging concepts in temporary-river ecology. Freshwater Biol. 55:717-738.

Likens GE, 1983. An ecosystem approach to aquatic ecology: mirror lake and its environment. Springer-Verlag, New York: $532 \mathrm{pp}$.

Lindeman RL, 1942. The trophic-dynamic aspect of ecology. Ecology 23:399-417.

Lomolino MV, 1989. Interpretations and comparisons of constants in the species-area relationship: an additional caution. Am. Nat. 133:71-75.

Lomolino MV, Riddle BR, Whittaker RJ, Brown JH, 2010. Biogeography, $4^{\text {th }}$ ed. Sinauer Associates, New York: 560 pp.

Loreau M, Mouquet N, Holt RD, 2003. Meta-ecosystems: a theoretical framework for a spatial ecosystem ecology. Ecol. Lett. 6:673-679.

MacArthur RH, Wilson EO, 1967. The theory of island biogeography. Princeton University Press, Princeton: $224 \mathrm{pp}$.

Maguire B Jr., 1963. The passive dispersal of small aquatic organisms and their colonization of isolated bodies of water. Ecol. Monogr. 33:161-185.

Manel S, Schwartz MK, Luikart G, Taberlet P, 2003. Landscape genetics: combining landscape ecology and population genetics. Trends Ecol. Evol. 18:189-497.

McIntosh RP, 1986. The background of ecology: concept and theory. Cambridge University Press, Cambridge: 400 pp.

Nekola JC, White PS, 1999. The distance decay of similarity in biogeography and ecology. J. Biogeogr. 26:867-878.

NRC CIAE (National Research Council, Committee on Inland Aquatic Ecosystems), 1996. Freshwater ecosystems: revitalizing educational programs in limnology. National Academy Press, Washington, DC.

Oberdorff T, Guilbert E, Lucchetta JC, 1993. Patterns of fish species richness in the Seine River basin, France. Hydrobiologia 259:157-167.

Oertli B, Joye DA, Castella E, Juge R, Cambin D, Lachavanne JD, 2002. Does size matter? The relationship between pond area and biodiversity. Biol. Conserv. 104:59-70.

Preston FW, 1960. Time and space and the variation of species. Ecology 41:612-627.

Reynolds CS, 1998. The state of freshwater ecology. Freshwater Biol. 39:741-753.

Rosenzweig ML, 1995. Species diversity in space and time. Cambridge University Press, Cambridge: 460 pp.

R Core Team, 2013. R: A Language and Environment for Statistical Computing. R Foundation for Statistical Computing, Vienna, Austria. Available from: http://www.R-project.org

Real LA, Brown JH, 1991. Foundations of ecology: classic papers with commentaries. University of Chicago Press: 920 pp.

Ricklefs RE, 1987. Community diversity: relative roles of local and regional processes. Science 235:167-171.

Ricklefs RE, Jenkins DG, 2011. Biogeography and ecology: towards the integration of two disciplines. Phil. T.R. Soc. B 366:2438-2448

Rigler FH, 1975. The concept of energy flow and nutrient flow between trophic levels, p. 15-26. In: W.H. van Dobben and R.H. Lowe-McConnell (eds.), Unifying concepts in ecology.
Report of the plenary sessions of the 1st Int. Congr. Ecology, The Hague, The Netherlands.

Ringelberg J, 1993. The growing difference between limnology and aquatic ecology. Neth. J. Aquat. Ecol. 27:11-19.

Scheffer M, Van Geest GJ, Zimmer K, Jeppesen E, Søndergaard M, Butler MG, Hanson MA, Declerck S, De Meester L, 2006. Small habitat size and isolation can promote species richness: second-order effects on biodiversity in shallow lakes and ponds. Oikos 112:227-231.

Schindler DW, 2006. Recent advances in the understanding and management of eutrophication. Limnol. Oceanogr. 51:356-363.

Schindler DW, Curtis PJ, Parker BR, Stainton MP, 1996. Consequences of climate warming and lake acidification for UVB penetration in North American boreal lakes. Nature 379:705-708.

Schoener TW, 1976. The species-area relation within archipelagos: models and evidence island land birds, p. 629-642. In: H.J. Firth and J.H. Calaby (eds.), Proc. $16^{\text {th }}$ Int. Australian Ornithological Conf., Australian Academy of Science, Canberra.

Schumm SA, Dumont JF, Holbrook JM, 2000. Active tectonics and alluvial rivers. Cambridge University Press: 276 pp.

Smol JP, 2008. Pollution of lakes and rivers: a paleoenvironmental perspective. Blackwell, Malden: 396 pp.

Stomp M, Huisman J, Mittelbach GG, Litchman E, Klausmeier CA, 2011. Large-scale biodiversity patterns in freshwater phytoplankton. Ecology 92:2096-2107.

Soininen J, Lennon JJ, Hillebrand H, 2007. A multivariate analysis of beta diversity across organisms and environments. Ecology 88:2830-2838.

Steinbauer MJ, Dolos K, Reineking B, Beierkuhnlein C, 2012. Current measures for distance decay in similarity of species composition are influenced by study extent and grain size. Global Ecol. Biogeogr. 21:1203-1212.

Taskinen S, Warton DI, 2011. Robust estimation and inference for bivariate line-fitting in allometry. Biometrical J. 53:652-672.

Tuomisto H, Ruokolainen K, 2006. Analyzing or explaining beta diversity? Understanding the targets of different methods of analysis. Ecology 87:2697-2708.

Van de Meutter F, De Meester L, Stoks R, 2007. Metacommunity structure of pond macroinvertebrates: effects of dispersal mode and generation time. Ecology 88:1687-1695.

Walker IR, Mathewes RW, 1989. Chironomidae (Diptera) remains in surficial lake sediments from the Canadian Cordillera: analysis of the fauna across an altitudinal gradient. J. Paleolimnol. 1:61-80.

Warton D, Duursma R, Falster D, Taskinen S, 2012. smatr 3 an $\mathrm{R}$ package for estimation and inference about allometric lines. Method. Ecol. Evol. 3:257-259.

Wetzel RG, 2001. Limnology: lake and river ecosystems, 3rd ed. Academic Press, San Diego: 1009 pp.

Xiao X, White EP, Hooten MB, Durham SL, 2011. On the use of log-transformation $v s$. nonlinear regression for analyzing biological power laws. Ecology 92:1887-1894. 